\title{
Proton magnetic resonance spectroscopy of the thalamus in patients with osteoarthritis of the hip
}

\section{T. Shigemura, \\ S. Kishida, \\ Y. Eguchi, \\ S. Ohtori, \\ J. Nakamura, \\ M. Kojima, \\ Y. Masuda, \\ K. Takahashi}

From Department of Orthopaedic Surgery,

Graduate School of

Medicine, Chiba

University, Chiba,

Japan

Bone Joint Res 2012;1:8-12. doi:10.1302/2046-

3758.1.1.2000018

Received 1 November 2011,

Accepted after revision 16

December 2011
- T. Shigemura, MD, Graduate student

- S. Kishida, MD, Assistant Professor

S. Ohtori, MD, Assistant Professor

J. Nakamura, MD, Clinical Fellow

K. Takahashi, MD, Professor Graduate School of Medicine, Chiba University, Department of Orthopaedic Surgery, 1-8-1 Inohana, Chuo-ku, Chiba, 2608670, Japan.

Y. Eguchi, MD, Orthopaedic Surgeon

Matsudo City Hospital, 4005

Kamihongo, Matsudo, 271-8511, Japan.

M. Kojima, RT, radiological technologist

Y. Masuda, RT, radiological

technologist

Chiba University Hospital,

Department of Radiology, 1-8-1

Inohana, Chuo-ku, Chiba, 260-

8670 , Japan.

Correspondence should be sent to $\mathrm{Dr} \mathrm{T}$. Shigemura; e-mail:

tshigepon@yahoo.co.jp

Objectives

The purpose of this study was to assess $\mathrm{N}$-acetyl aspartate changes in the thalamus in patients with osteoarthritis of the hip using proton magnetic resonance spectroscopy.

\section{Methods}

Nine patients with osteoarthritis of the hip (symptomatic group, nine women; mean age 61.4 years (48 to 78$)$ ) and nine healthy volunteers (control group, six men, three women; mean age 30.0 years (26 to 38 )) underwent proton magnetic resonance spectroscopy to assess the changes of $\mathrm{N}$-acetyl aspartate in the thalamus.

\section{Results}

The ratio of $\mathrm{N}$-acetyl aspartate to creatine plus phosphocreatine in the thalamus contralateral to the symptomatic hip in patients with osteoarthritis of the hip was significantly lower than the ratio of $\mathrm{N}$-acetyl aspartate to creatine plus phosphocreatine in the thalamus in the control group (1.611; (1.194 to 1.882) vs 1.355 (1.043 to 1.502), $\mathrm{p}<0.001$ ). Also, a strong negative correlation was detected between the ratio of $\mathrm{N}$-acetyl aspartate to creatine plus phosphocreatine in the thalamus contralateral to the symptomatic hip in patients with osteoarthritis of the hip and pain duration $(r=-0.83, p=0.018)$.

\section{Conclusions}

We evaluated the ratio of $\mathrm{N}$-acetyl aspartate to creatine plus phosphocreatine in the thalamus of patients with osteoarthritis of the hip by using proton magnetic resonance spectroscopy. We concluded that the ratio of $\mathrm{N}$-acetyl aspartate to creatine plus phosphocreatine in the thalamus contralateral to the symptomatic hip in patients with osteoarthritis of the hip were significantly lower than those in the thalamus of the control group, and that pain duration was strongly related to the decrease of the ratio of $\mathrm{N}$-acetyl aspartate to creatine plus phosphocreatine.

Keywords: Hip joint, Osteoarthritis (OA), Proton Magnetic Resonance Spectroscopy (1 H-MRS), Thalamus, $\mathrm{N}$-acetyl aspartate (NAA), Chronic pain

\section{Article focus}

The purpose of our study was to assess the functional change of the thalamus in patients with osteoarthritis of the hip using proton magnetic resonance spectroscopy.

\section{Key messages}

The ratio of $\mathrm{N}$-acetyl aspartate to creatine plus phosphocreatine in the thalamus contralateral to the symptomatic hip in the patients with osteoarthritis of the hip was significantly lower than the ratio of $\mathrm{N}$-acetyl aspartate to creatine plus phosphocreatine in the thalamus in control patients. We also detected a strong negative correlation between the $\mathrm{N}$-acetyl aspartate of the thalamus contralateral to the symptomatic hip in patients with osteoarthritis when compared with the duration of pain.

Strengths and limitations of the study This is the first study to our knowledge to assess the changes of $\mathrm{N}$-acetyl aspartate in the thalamus in patients with osteoarthritis of the hip using proton magnetic resonance spectroscopy. The limitations of this study are that we only evaluated a small number of patients and that it was not a longitudinal study.

\section{Introduction}

Osteoarthritis (OA) is one of the most common causes of chronic pain, affecting many 
different joints including the hip. The prevalence of $\mathrm{OA}$ of the hip is estimated to be $7.4 \%$ in the elderly population, ${ }^{1}$ and this is expected to rise alongside ageing populations. ${ }^{2}$ However, to our knowledge, the pathomechanism of OA of the hip has been never clarified. Gwilym et al $^{3}$ reported the atrophy of the thalamus contralateral to the symptomatic hip joint in patients with OA using voxel-based morphometry, which is a method of assessing the volume of brain gray matter using high-resolution three-dimensional (3D) MRI. The study also showed a reversal of thalamic atrophy after arthroplasty of the affected hip, alongside an associated decrease in pain and increase in function. ${ }^{3}$ These findings revealed that the morphological changes of the thalamus have an important role for pathomechanism of chronic pain.

Proton magnetic resonance spectroscopy ( $\left.{ }^{1} \mathrm{H}-\mathrm{MRS}\right)$ is a non-invasive method of measuring concentrations of intracellular metabolites with MRI. The main metabolites detected by ${ }^{1} \mathrm{H}$-MRS in the central nervous system are $\mathrm{N}$ acetyl aspartate (NAA), creatine plus phosphocreatine $(\mathrm{Cr})$, choline-containing compounds (cho), and myoinositol ( $\mathrm{ml})$. NAA is located primarily in neurons, and its concentration is considered to reflect neural activity or function. ${ }^{4,5}$ Several studies have reported decreased levels of NAA in patients with herpes simplex encephalitis, ${ }^{6}$ Alzheimer's disease, ${ }^{7,8}$ steno-occlusive carotid artery disease, ${ }^{9}$ epilepsy, ${ }^{10}$ acute traumatic brain injury ${ }^{11}$ and stroke. ${ }^{12,13}$ Decreased levels of NAA were also observed in the thalamus of patients with chronic pain. Fukui et al ${ }^{14}$ reported a decreased concentration of NAA in the thalamus in patients with neuropathic pain, and Pattany et al ${ }^{15}$ reported that the concentration of NAA in the thalamus were significantly lower in patients with pain after spinal cord injury than patients without pain. These studies suggest that functional changes of the thalamus contribute to the pathomechanism of chronic pain. Thus, we hypothesised that a functional change of the thalamus would be observed in patients with OA of the hip.

The purpose of our study was to assess the functional change of the thalamus in patients with OA of the hip using ${ }^{1} \mathrm{H}$-MRS.

\section{Materials and Methods}

Patients. Nine patients (nine women, mean age 61.4 years (48 to 78)) with a diagnosis of unilateral OA of the hip, unilateral hip pain and radiologically identified deformity of the hip were evaluated using ${ }^{1} \mathrm{H}-\mathrm{MRS}$. Radiological findings revealed that all affected hip joints in the OA group were grade 4 on the Kellgren and Lawrence classification. ${ }^{16}$ No patient had OA of another joint. A control group comprising nine healthy patients (six men, three women, mean age 30.0 years ( 26 to 38 )) also underwent evaluation by ${ }^{1} \mathrm{H}-\mathrm{MRS}$. No patient had ever had joint pain. Hip pain was evaluated using a visual analogue scale (VAS) which was scored between 10 (extreme pain) and 0 (no pain). ${ }^{17,18}$

The study was approved by the ethical committee of Chiba University Hospital, and adhered to the Helsinki Declaration. All patients provided written informed consent for participation in the study. All ${ }^{1} \mathrm{H}$-MRS procedures were conducted in accordance with institutional guidelines.
${ }^{1}$ H-MRS protocol. ${ }^{1} \mathrm{H}-\mathrm{MRS}$ was performed using a three-tesla (3T) whole-body MRI system (Discovery MR750; General Electric Company, Milwaukee, Wisconsin). Anatomical MRI scans were obtained with axial and coronal $\mathrm{T}_{2}$-weighted fast spinecho sequence (repetition time, $4000 \mathrm{~ms}$; echo time, $102 \mathrm{~ms}$ ). Slices were $4 \mathrm{~mm}$ thick, and the matrix was $256 \mathrm{~mm} \times 320$ $\mathrm{mm}$. A $15 \mathrm{~mm} \times 15 \mathrm{~mm} \times 15 \mathrm{~mm}$ volume of interest was selected in each thalamus. The MRI spectra consistently showed two major peaks corresponding to NAA and Cr. We calculated the ratio of NAA to $\mathrm{Cr}$, which is known to remain stable under various pathologic conditions and commonly used as an internal standard. ${ }^{19-21}$

Statistical analysis. In previous studies of patients with chronic pain, morphological or functional changes of the thalamus contralateral to the symptomatic side have been reported. $3,22,23$ Then, the contralateral thalamus has been considered to have an important role in the processing of central pain..$^{3,22,23}$ We therefore compared the ratio of NAA to $\mathrm{Cr}$ in the thalamus contralateral to the symptomatic hip in patients with OA with those of the control group using the Mann-Whitney $U$ test. We also compared the ratio of $\mathrm{NAA}$ to $\mathrm{Cr}$ in the thalamus contralateral to the symptomatic hip with those of the thalamus ipsilateral to the symptomatic hip using the Mann-Whitney $U$ test. Next, we investigated the correlation between the ratio of NAA to $\mathrm{Cr}$ in the thalamus contralateral to the symptomatic hip and the VAS using the Spearman's rank correlation coefficient test. Finally, we investigated the correlation between the ratio of NAA to $\mathrm{Cr}$ in the thalamus contralateral to the symptomatic hip and pain duration using the Spearman's rank correlation coefficient test. A p-value $<0.05$ was considered to indicate statistical significance.

\section{Results}

The clinical characteristics of the nine patients with OA of the hip are shown in Table I. The mean duration of pain was 3.5 years (1.1 to 7.0) and the mean VAS pain score was 6.1 (1.2 to 9.0). The MRS data of the OA and control groups are shown in Table II and Table III, respectively. The mean ratio of NAA to $\mathrm{Cr}$ in the control group was 1.630 (1.267 to 2.038) for the right thalamus and 1.592 (1.120 to 1.880) for the left thalamus, which did not reach statistical significance (Mann-Whitney $U$ test, $p=0.89$ ). The NAA to $\mathrm{Cr}$ ratio for the two sides were therefore averaged and used as a control value. The mean NAA to $\mathrm{Cr}$ ratio of the contralateral thalamus to the symptomatic hip in the patients with OA were significantly lower than those of the thalamus in the control group (1.355 (1.043 to 1.502$)$ versus 1.611 (1.194 to 1.882$), p<0.001)$. There was no significant difference between the mean NAA to $\mathrm{Cr}$ ratio of the thalamus contralateral to and the thalamus ipsilateral to the symptomatic hip joint in the patients with OA of the hip (1.355 (1.043 to 1.502 ) versus 1.430 (1.087 to 1.875$), p=0.69)$. No correlation was identified between the mean ratio of NAA to $\mathrm{Cr}$ of the thalamus contralateral to the symptomatic hip in the patients with OA of the hip and VAS (Fig. 1, p = 0.89). A strong negative correlation was observed between the mean ratio of NAA to $\mathrm{Cr}$ in the thalamus contralateral to the symptomatic hip in the patients with OA of the hip and pain duration (Fig. 2, $r=-0.83, p=0.018$ ). 
Table I. Clinical characteristics of the nine patients with osteoarthritis of the hip joint

\begin{tabular}{llll}
\hline $\begin{array}{l}\text { Number/Gender/ } \\
\text { Age (yrs) }\end{array}$ & Site of hip pain & Pain duration (yrs) & Pain score $^{*}$ \\
\hline 1 / F / 48 & Left & 1.1 & 4.9 \\
2 / F / 77 & Right & 6.0 & 9.0 \\
3 / F / 78 & Left & 2.8 & 7.3 \\
4 / F / 60 & Left & 3.0 & 7.1 \\
5 / F / 53 & Left & 1.1 & 8.2 \\
6 / F / 59 & Right & 3.9 & 5.0 \\
7 / F / 56 & Left & 5.6 & 1.2 \\
8 / F / 62 & Right & 1.2 & 5.3 \\
9 / F / 60 & Left & 7.0 & 6.6 \\
Mean (range) & & $3.5(1.1$ to 7.0$)$ & $6.1(1.2$ to 9.0) \\
\hline
\end{tabular}

* measured by a visual analogue scale

Table II. The Magnetic Resonance Spectroscopy data for the nine patients with osteoarthritis of the hip (NAA, N-acetyl aspartate; $\mathrm{Cr}$, creatine plus phosphocreatine)

\begin{tabular}{|c|c|c|c|}
\hline $\begin{array}{l}\text { Number/Gender/ } \\
\text { Age (yrs) }\end{array}$ & $\begin{array}{l}\text { Ratio of NAA to } \mathrm{Cr} \\
\text { (ipsilateral side) }\end{array}$ & $\begin{array}{l}\text { Ratio of NAA to } \mathrm{Cr} \\
\text { (contralateral side) }\end{array}$ & p-value ${ }^{*}$ \\
\hline $1 / F / 48$ & 1.875 & 1.495 & \\
\hline 2 / F / 77 & 1.797 & 1.193 & \\
\hline $3 / F / 78$ & 1.549 & 1.502 & \\
\hline $4 / F / 60$ & 1.213 & 1.410 & \\
\hline $5 / F / 53$ & 1.422 & 1.439 & \\
\hline $6 / F / 59$ & 1.294 & 1.426 & \\
\hline $7 / F / 56$ & 1.154 & 1.191 & \\
\hline $8 / F / 62$ & 1.474 & 1.491 & \\
\hline $9 / F / 60$ & 1.087 & 1.043 & \\
\hline Mean (range) & $1.430(1.087$ to 1.875$)$ & 1.355 (1.043 to 1.502$)$ & 0.69 \\
\hline
\end{tabular}

* Mann-Whitney U test

Table III. The Magnetic Resonance Spectroscopy data of the control group (NAA, N-acetyl aspartate; $\mathrm{Cr}$, creatine plus phosphocreatine)

\begin{tabular}{llll}
\hline $\begin{array}{l}\text { Number/Gender/ } \\
\text { Age (yrs) }\end{array}$ & $\begin{array}{l}\text { Ratio of NAA to } \mathbf{C r} \\
\text { (right side) }\end{array}$ & $\begin{array}{l}\text { Ratio of NAA to } \mathbf{C r} \\
\text { (left side) }\end{array}$ & p-value \\
\hline 1 / M / 38 & 1.659 & 1.688 \\
2 / M / 28 & 1.777 & 1.668 \\
3 / F / 29 & 1.498 & 1.765 \\
4 / M / 29 & 1.518 & 1.588 \\
5 / F / 26 & 1.625 & 1.538 \\
6 / M / 32 & 1.571 & 1.356 \\
7 / F / 32 & 2.038 & 1.726 \\
8 / M / 29 & 1.267 & 1.120 \\
9 / M / 27 & 1.713 & 1.880 \\
Mean (range) & 1.630 (1.267 to 2.038) & $1.592(1.120$ to 1.880) 0.89 \\
\hline * Mann-Whitney U test
\end{tabular}

* Mann-Whitney U test

\section{Discussion}

The present ${ }^{1} \mathrm{H}$-MRS data suggested that the ratio of NAA to $\mathrm{Cr}$ in the thalamus contralateral to the symptomatic hip in the patients with OA of the hip were significantly lower than the ratio of NAA to $\mathrm{Cr}$ of the thalamus in the control group $(p<0.001)$. In addition, a strong negative correlation was observed between the ratio of NAA to $\mathrm{Cr}$ of the thalamus contralateral to the symptomatic hip in the patients with OA of the hip and duration of pain $(r=-0.83$, $p=0.018$ ).
There have been several studies which revealed that functional changes of the thalamus contralateral to the symptomatic side in chronic pain patients. ladarola et al ${ }^{22}$ reported that the activities of the thalamus contralateral to the symptomatic side were decreased in patients with neuropathic pain when using positron emission tomography. Fukumoto et $\mathrm{al}^{23}$ reported that hypoperfusion of the thalamus contralateral to the symptomatic side were observed in long-term patients with reflex sympathetic dystrophy syndrome (RSDS) by using single photon emission computed tomography (SPECT). The 


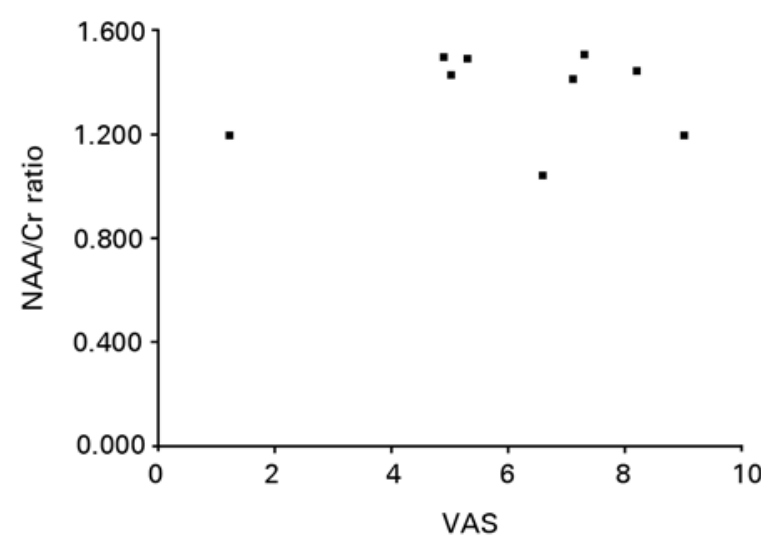

Fig. 1

Scatter graph showing the relationship between the ratio of NAA to $\mathrm{Cr}$ in the thalamus contralateral to the symptomatic hip in patients with osteoarthritis of the hip and pain as measured by a visual analogue scale (VAS). No correlation was identified between the ratio of NAA to $\mathrm{Cr}$ and VAS.

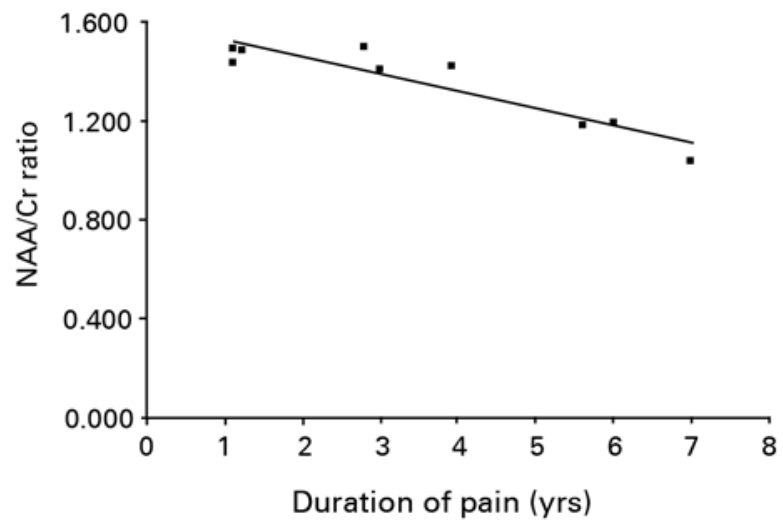

Fig. 2

Scatter graph showing the relationship between the ratio of NAA to $\mathrm{Cr}$ in the thalamus contralateral to the symptomatic hip in patients with osteoarthritis of the hip and the duration of pain. A significant negative correlation between the ratio of NAA to $\mathrm{Cr}$ and pain duration was observed $(r=-0.82, p=0.044)$.

present study suggested the decrease of NAA levels in the thalamus contralateral to the symptomatic hip in patients with $\mathrm{OA}$ of the hip. Fukui ${ }^{24}$ reported on the relationship between the ratio of NAA to $\mathrm{Cr}$ in the thalamus measured by ${ }^{1} \mathrm{H}-\mathrm{MRS}$, and regional cerebral blood flow in the thalamus measured by stable xenon-enhanced computed tomography. Our study indicated functional changes of thalamus contralateral to the symptomatic hip joint in patients with OA of the hip. This is the first study to evaluate the thalamus of patients with OA of the hip using ${ }^{1} \mathrm{H}-\mathrm{MRS}$.

The relationship between pain intensity and functional change of the thalamus is controversial. Fukumoto et $\mathrm{al}^{23}$ reported that pain intensity was not correlated with contralateral thalamic perfusion in patients with RSDS by a SPECT study, although Pattany et $\mathrm{al}^{15}$ showed that pain intensity was negatively correlated with the concentration of NAA in the thalamus in patients with spinal cord injury in a study using ${ }^{1} \mathrm{H}-\mathrm{MRS}$. In accordance with the study of Fukumoto et al, ${ }^{23}$ no correlation was observed between the ratio of NAA to $\mathrm{Cr}$ in the thalamus and the VAS for pain in this study.

We hypothesised that a correlation existed between a decrease in NAA and the duration of pain. In agreement with our hypothesis, the ratio of NAA to $\mathrm{Cr}$ of the thalamus contralateral to the symptomatic hip in the patients with OA of the hip was negatively correlated with duration of pain. Fukumoto et $\mathrm{al}^{23}$ also suggested that a decrease of the contralateral thalamic uptake index was correlated with the time since onset on the basis of a SPECT study. These results suggested that duration of pain was associated with a functional change in the thalamus.

The present study has several limitations. First, the mean age of the patients with OA of the hip was higher than that of the control group (61.4 vs 30.0, $p<0.001)$. This difference may have resulted in an age-dependent difference in the ratio of NAA to $\mathrm{Cr}$. However, several studies have shown that metabolic changes in the brain associated with aging occur almost entirely within the first two years of life ${ }^{25-27}$; only minimal changes occur thereafter, and adult concentrations are achieved by the age of 20 years. ${ }^{28}$ Furthermore, Fukui et al ${ }^{14}$ reported the MRS data of 14 healthy volunteers with an age range between 23 and 64 years and found no age-related change in the mean NAA concentration. Thus, the age difference between the two groups in our study is unlikely to account for the observed metabolic changes. Second, the patients who participated in this study were all women. No men with OA of the hip participated. Thus, further analysis is required to clarify the existence of any potential genderrelated differences in the ratio of NAA to $\mathrm{Cr}$ in patients with OA of the hip. Third, only a small number of patients were evaluated. Further studies are required to determine whether the present findings remain valid in a larger population. Finally, we were not able to repeat ${ }^{1} \mathrm{H}-\mathrm{MRS}$ after surgery, due to artefacts induced by total hip arthroplasty implants.

\section{Conclusion}

The ratio of NAA to $\mathrm{Cr}$ were lower in patients with chronic hip pain, suggesting an association between chronic hip pain and functional changes in the thalamus. ${ }^{1} \mathrm{H}-\mathrm{MRS}$ can be used to detect decreased thalamic neural activity in clinical practice. Future studies will be important for understanding whether or not the decreased ratio of NAA to $\mathrm{Cr}$ can be resolved by surgical or pharmacological treatment.

\section{References}

1. Quintana JM, Arostegui I, Escobar A, et al. Prevalence of knee and hip osteoarthritis and the appropriateness of joint replacement in an older population. Arch Intern Med 2008;168:1576-1584.

2. Lawrence RC, Felson DT, Helmick CG, et al. Estimates of the prevalence of arthritis and other rheumatic conditions in the United States. Part II. Arthritis Rheum 2008;58:26-35.

3. Gwilym SE, Filippini N, Douaud G, Carr AJ, Tracey I. Thalamic atrophy associated with painful osteoarthritis of the hip is reversible after arthroplasty: a longitudinal voxel-based morphometric study. Arthritis Rheum 2010;62:2930-2940.

4. Bhakoo KK, Pearce D. In vitro expression of $\mathrm{N}$-acetyl aspartate by oligodendrocytes: implications for proton magnetic resonance spectroscopy signal in vivo. J Neurochem 2000;74: 254-262. 
5. Urenjak J, Williams SR, Gadian DG, Noble M. Specific expression of $\mathrm{N}$-acetylaspartate in neurons, oligodendrocyte-type-2 astrocyte progenitors, and immature oligodendrocytes in vitro. I Neurochem 1992;59:55-61.

6. Menon DK, Sargentoni J, Peden CJ, et al. Proton MR spectroscopy in herpes simplex encephalitis: assessment of neuronal loss. J Comput Assist Tomogr 1990;14:449-452.

7. Jessen F, Block W, Träber F, et al. Proton MR spectroscopy detects a relative decrease of $\mathrm{N}$-acetylaspartate in the medial temporal lobe of patients with AD. Neurology 2000;55:684-688.

8. Shonk TK, Moats RA, Gifford P, et al. Probable Alzheimer disease: diagnosis with proton MR spectroscopy. Radiology 1995;195:65-72.

9. Tsuchida C, Kimura H, Sadato N, et al. Evaluation of brain metabolism in steno-occlusive carotid artery disease by proton MR spectroscopy: a correlative study with oxygen metabolism by PET. I Nucl Med 2000;41:1357-1362.

10. Martin RC, Sawrie S, Hugg J, et al. Cognitive correlates of 1H MRSIdetected hippocampal abnormalities in temporal lobe epilepsy. Neurology 1999;53:2052-2058.

11. Ross BD, Ernst T, Kreis R, et al. $1 \mathrm{H}$ MRS in acute traumatic brain injury. J Magn Reson Imaging 1998;8:829-840.

12.Bruhn H, Frahm J, Gyngell ML, et al. Cerebral metabolism in man after acute stroke: new observations using localized proton NMR spectroscopy. Magn Reson Med 1989;9:126-131.

13. Graham GD, Blamire AM, Howseman AM, et al. Proton magnetic resonance spectroscopy of cerebral lactate and other metabolites in stroke patients. Stroke 1992;23:333-340.

14. Fukui S, Matsuno $M$, Inubushi T, Nosaka S. N-Acetylaspartate concentrations in the thalami of neuropathic pain patients and healthy comparison subjects measured with (1)H-MRS. Magn Reson Imaging 2006;24:75-79.

15. Pattany PM, Yezierski RP, Widerström-Noga EG, et al. Proton magnetic resonance spectroscopy of the thalamus in patients with chronic neuropathic pain after spinal cord injury. AJNR Am J Neuroradiol 2002;23:901-905.

16. Kellgren JH, Lawrence JS. Radiologic assessment of osteo-arthrosis. Ann Rheum Dis 1957;16:494-502.

17. Jensen MP, Karoly P. Self-report scales and procedures for assessing pain in adults. In: Turk DC, Melzack R, eds. Handbook of pain assessment. New York: Guilford Press, 1992:135-151.

18. Price DD, Harkins SW. Psychophysical approaches to pain measurement and assessment. In: Turk DC, Melzack R, eds. Handbook of pain assessment. New York: Guilford Press, 1992:111-134.

19. Frahm J, Bruhn H, Gyngell ML, et al. Localized proton NMR spectroscopy in different regions of the human brain in vivo: relaxation times and concentrations of cerebral metabolites. Magn Reson Med 1989;11:47-63.
20.Gill SS, Thomas DG, Van Bruggen N, et al. Proton MR spectroscopy of intracranial tumours: in vivo and in vitro studies. / Comput Assist Tomogr 1990; 14:497-504.

21.Sappey-Marinier D, Calabrese G, Hetherington HP, et al. Proton magnetic resonance spectroscopy of human brain: applications to normal white matter, chronic infarction, and MRI white matter signal hyperintensities. Magn Reson Med 1992;26:313-327.

22.Iadarola MJ, Max MB, Berman KF, et al. Unilateral decrease in thalamic activity observed with positron emission tomography in patients with chronic neuropathic pain. Pain 1995;63:55-64.

23. Fukumoto $M$, Ushida T, Zinchuk VS, Yamamoto H, Yoshida S. Contralateral thalamic perfusion in patients with reflex sympathetic dystrophy syndrome. Lancet 1999;354:1790-1791.

24. Fukui S. Evaluation of thalamic neural activity in CRPS type 1 patients by proton MR spectroscopy: a correlative study with rCBF. J Anesth 2003; 17:142-144.

25. Hüppi PS, Posse S, Lazeyras F, et al. Magnetic resonance in preterm and term newborns: $1 \mathrm{H}$-spectroscopy in developing human brain. Pediatr Res 1991;30:574-578.

26. Kimura $\mathrm{H}$, Fujii $\mathrm{Y}$, Itoh $\mathrm{S}$, et al. Metabolic alterations in the neonate and infant brain during development: evaluation with proton MR spectroscopy. Radiology 1995;194:483-489.

27. Kreis R, Ernst T, Ross BD. Development of the human brain: in vivo quantification of metabolite and water content with proton magnetic resonance spectroscopy. Magn Reson Med 1993;30:424-437.

28. Pouwels PJ, Brockmann $K$, Kruse B, et al. Regional age dependence of human brain metabolites from infancy to adulthood as detected by quantitative localized proton MRS. Pediatr Res 1999;46:474-485.

\section{Funding statement: \\ None declared}

Author contributions:

- T. Shigemura: Data analysis, Data acquisition, Study design

- S. Kishida: Data acquisition, Study design

S. Ohtori: Study design

I. Nakamura: Data acquisition

- K. Takahashi: Study design

Y. Eguchi: Data analysis, Study design

- M. Kojima: Data acquisition

Y. Masuda: Data acquisition

ICMJE Conflict of Interest:

- None declared

(9)2012 British Editorial Society of Bone and Joint Surgery. This is an open-access article distributed under the terms of the Creative Commons Attributions licence, which permits unrestricted use, distribution, and reproduction in any medium, but not for commercial gain, provided the original author and source are credited 